\title{
Learning from "Listening to Communities"
}

\section{MICHAEL VALLIANT AND MEGAN BETZ}

Community voice has persistently, and to degrees, been present in pockets of curricular and co-curricular community engagement at Indiana University - Bloomington (IUB). The Bloomington Volunteer Network (BVN), a program of the City of Bloomington, was instrumental in creating service-learning infrastructure on campus over 20 years ago and continues participation in regular meetings of campus-community stakeholders. Centering community voice in campus activities requires deliberate action by campus to create space to hear from community stakeholders. This is particularly true on a large, decentralized campus. Bloomington is described as a college town and houses the main campus of the Indiana University system. IUB hosts 43,503 students, ${ }^{1}$ who are included in the estimated Bloomington population of $84,067 .^{2}$

The Listening to Communities (LTC) structure supported by Indiana
Campus Compact (ICC) are formal methods employed by the Service-Learning Program (SLP), housed in the Center for Innovative Teaching and Learning (CITL), to engage a broad range of community agencies in conversation about our ongoing partnerships and engagement. Since 2013, SLP has hosted four LTC conversations evolving from setting priorities for the program to expanding on community-identified themes around engagement. The most recent was a two-part event using the LTC structure to solicit community partners' concerns, questions, and interest in campus-community partnerships.

Lucy Schaich, BVN Coordinator, and Efrat Feferman, United Way of Monroe County Executive Director, co-facilitated the events to ensure conversation centered on community. Through our partnership with BVN, we secured a room in City Hall and offered free parking for both

\section{MICHAEL VALLIANT}

Service-Learning Program Director, Indiana University Bloomington

\section{MEGAN BETZ}

Instructional Consultant/ Community Engagement Coordinator, Indiana University Bloomington

\footnotetext{
${ }^{1}$ U.S. News \& World Report. (2019). Overview of Indiana University-Bloomington. Retrieved from https://www.usnews.com/best-colleges/indiana-university-bloomington-18092

${ }^{2}$ City of Bloomington Office of the Mayor. (2019). Bloomington Census Data. Retrieved from https:// bloomington.in.gov/about/censusdata
} 


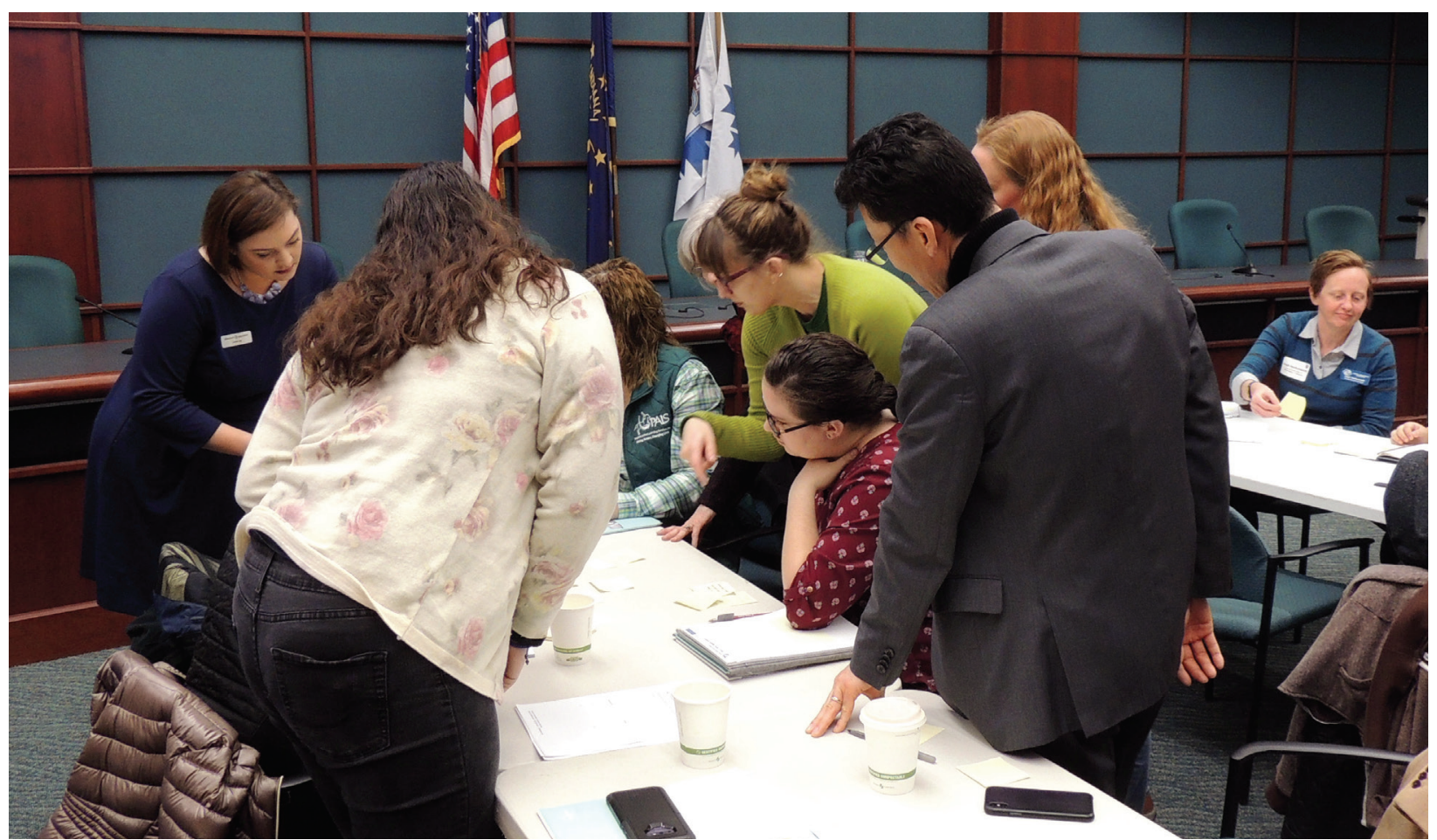

Representatives from area nonprofits and public entities work together on an affinity mapping exercise to determine their top priorities and questions they would like to resolve over the course of the day. Photo credit: Michael Valliant -

conversations. Our winter LTC, hosted December 13, brought together 42 attendees from 32 community organizations and three IUB programs. The spring event, hosted April 18, had 16 attendees from 11 community organizations. ${ }^{3}$ Attendees represented nonprofits working in Monroe County, predominantly serving Bloomington; due to this geographic focus and a similar restriction for most service-learning, conversation centered on Bloomington. Across both events, 39 unique community organizations attended with strong representation from youth-serving organizations and human services.

Our goals were to develop a community-guided understanding of opportunities for campus- community collaboration and offer better support of the community. The fall event included several conversations. First, we asked the community to set topics of conversation; these centered on barriers to creating needed partnerships. We then completed SWOT analyses and mapping activities to explore how spatial, structural, and skill barriers create gaps in IUB students' service to the community.

The best outcome of these events was creating often requested space for networking and resource-sharing. In spring, we invited representatives from three agencies ${ }^{4}$ to present on their experience with service-learners. Following the presentations and time for discussion, rather than

\footnotetext{
${ }^{3}$ To minimize the dominant power of an institution the size of IUB, we limited representation in the room. Neither students nor faculty were invited to the event. In our experience, community partners are more candid and disclose a fuller picture of their experience working with students when neither population is present.

${ }^{4}$ Immense thanks to Liz Grenat, Executive Director of Community Justice and Mediation Center; Scott Evans, Community In Schools - Site Coordinator at Templeton Elementary; and Choonhyun Jeon of the Monroe County Community School Corporation's Cultural Competency and Diversity Coordinator for sharing their experience creating a range of service - learning and community engagement opportunities for IUB students.
} 


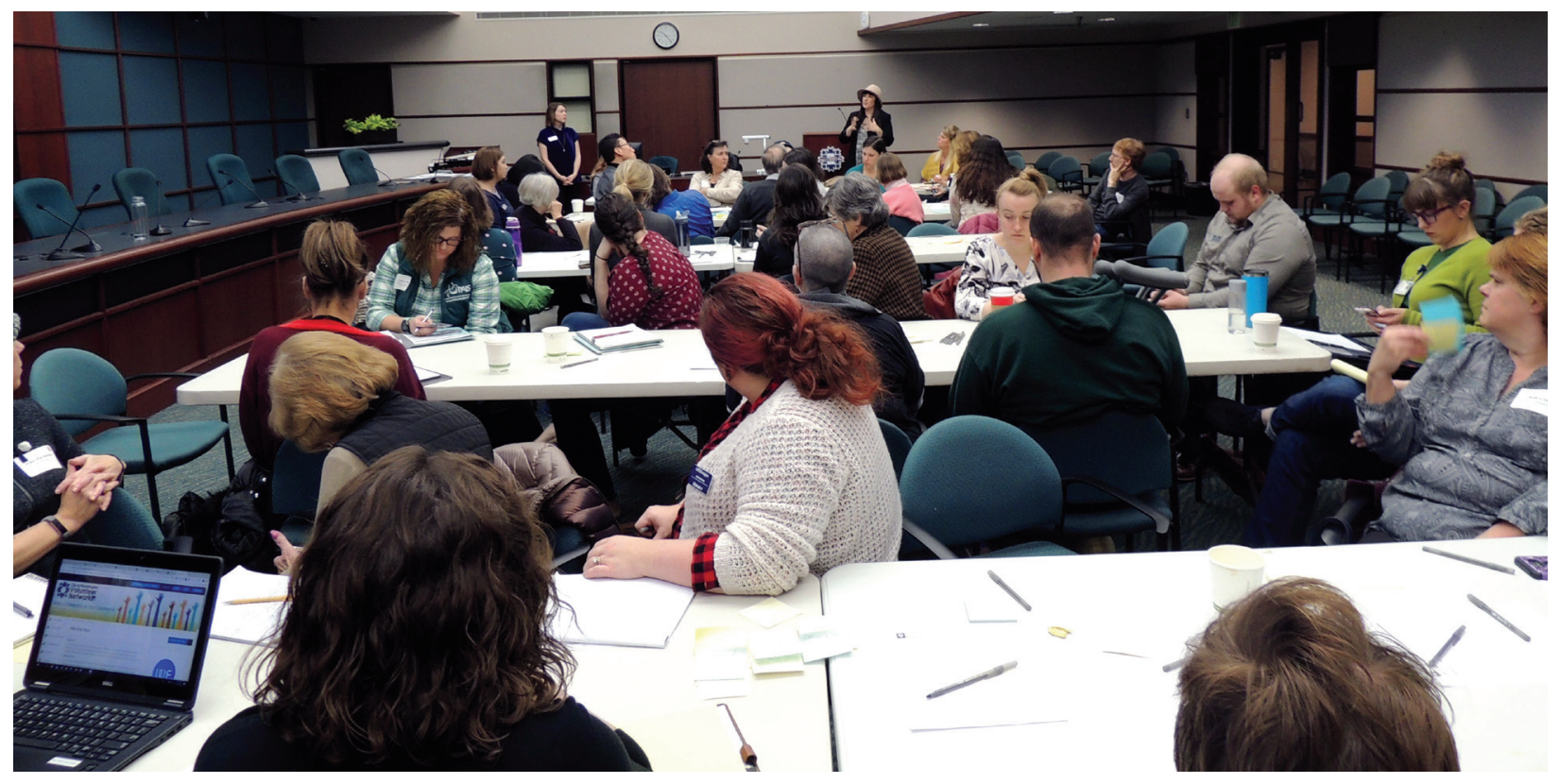

Attendees gathered to learn more about community-engaged learning opportunities. Here, Jessica Adams, ACE Program Coordinator, explains how our student employees (Advocates for Community Engagement) support agencies throughout Bloomington. Photo credit: Michael Valliant

moving into the planned sessions, we adapted to interest in continuing the morning's conversations. Moving chairs into a circle, we shared what makes a successful partnership and what support and resources could facilitate better partnerships.

Partners shared how the structure of academia impacts their work. Decentralization and shifts in instructor assignment and course offerings complicates partnership management. Further, while we frame service-learning as responsive to community need, partners argue they are still responding to campus-identified needs. Agencies want to be accommodating in support of student learning; many take on partnerships resulting in outputs duplicating past student efforts or requiring additional work to improve quality and utility.

Moving forward, following Lucy's advice reflecting on the events, we will seek input from community partners as we set goals for the day, inviting them to take ownership of sessions. We will also con- tinue conversation by hosting more networking events. Following Efrat's advice, we will further research what work has already addressed similar questions to those on our agenda and increase time preparing facilitators, ensuring they understand objectives and are prepared to support conversation.

Lucy also highlighted the importance of reporting results in an accessible format to support the investment made by partners in the conversation. Following the fall LTC, we prepared a report that was distributed to attendees for additional input, then to the community broadly through BVN's newsletter. A similar report is in preparation for the spring conversation, which will ask how the community would like to continue conversations about shared work. To share results with campus community-engaged professionals, we shared results at our in-house spring conference, on the CITL blog 5 , and at the 2019 ICC Service Engagement Summit.

${ }^{5}$ See the blog post here: https://blogs.iu.edu/citl/2019/06/12/listening-to-communities/\#.XYEbydNKgWo 


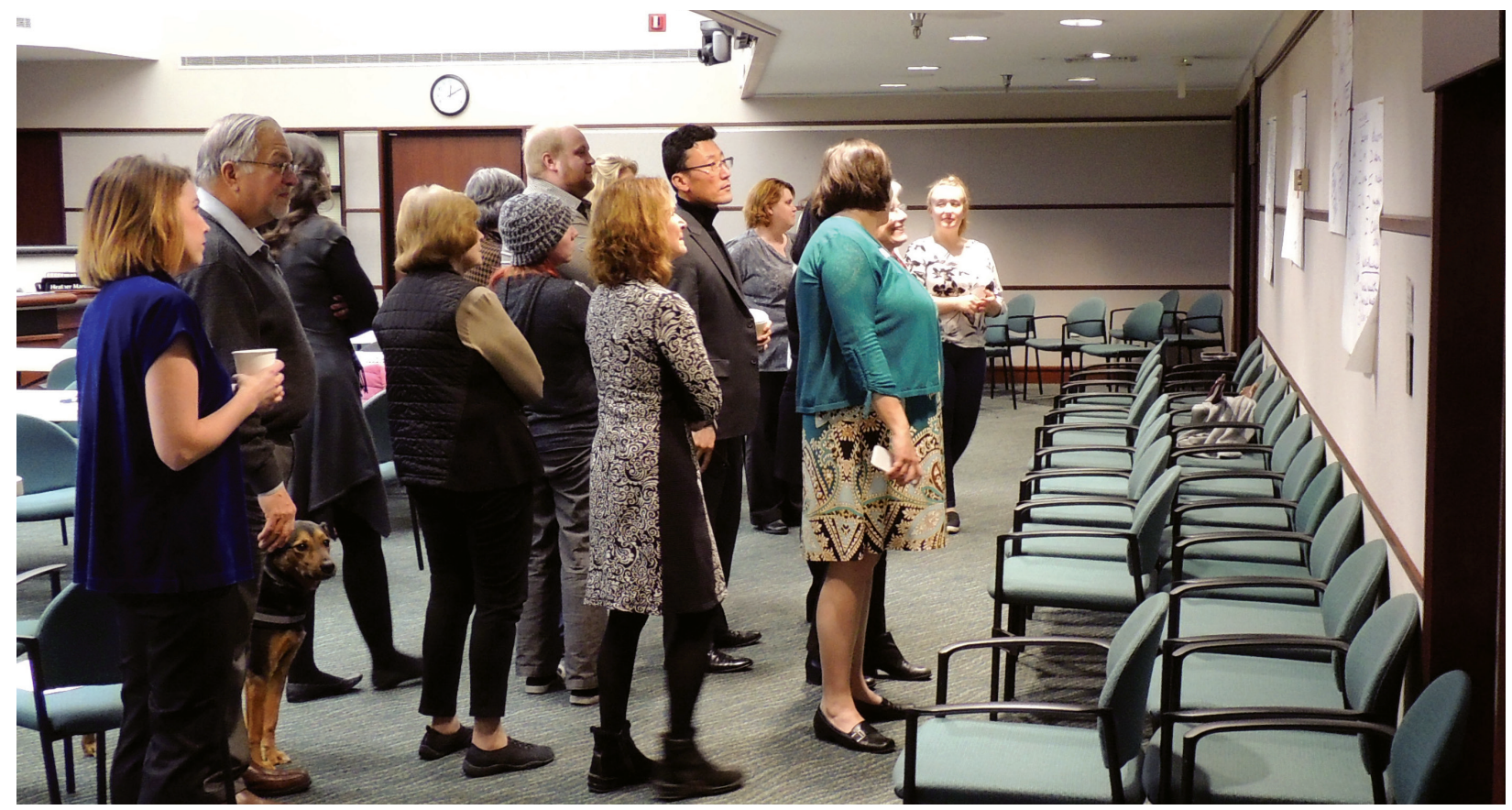

Attendees gather to look at and discuss concept maps they created to visualize their understanding of how communityengaged learning and campus-community partnerships support the Bloomington community. Photo credit: Michael Valliant

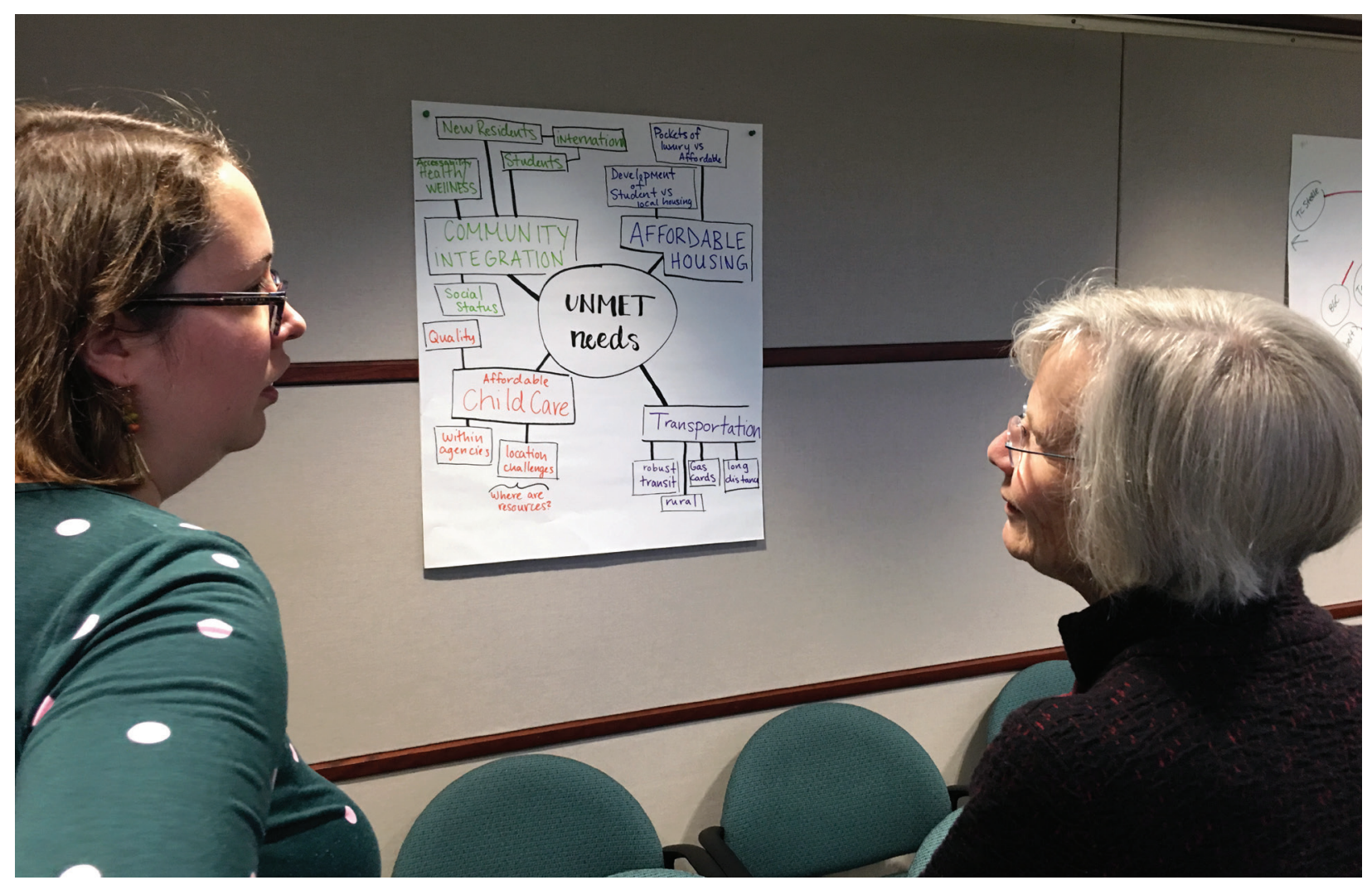

Two representatives from area nonprofits discuss a concept map attendees created, sharing the barriers they believe prevent more widespread community engagement. Photo credit: Michael Valliant 